\title{
Fine Needle Aspiration Cytology of Warthin's Tumor: A case report.
}

\author{
Dr. Manisha Tambekar. M.D ${ }^{1}$, Dr. Shilpi Sahu. M.D ${ }^{2}$, \\ Dr. Dharamdas Borkar. M.D ${ }^{3}$, Dr. Sakshi Garg. MBBS ${ }^{4}$. \\ Pathology, MGM Medical College, India
}

\begin{abstract}
Warthin's tumor, also known as papillary cystadenoma lymphomatosum or adenolymphoma, is the second most common benign tumor of the salivary glands. It arises exclusively in lower part of the parotid gland and affects mainly male in sixth or seventh decades of life. Studies have shown that there is a close association between Warthin's tumor and cigarette smoking. Preoperative fine needle aspiration cytology (FNAC) of a parotid mass plays a pivotal role in differentiating neoplastic from inflammatory lesion as well as management of patients. We report a case of a 35year old male, smoker who presented with painless swelling in the left parotid region.
\end{abstract}

Keywords- Fine needle aspiration cytology, Parotid gland, Squamous metaplasia, Warthin's tumor

\section{INTRODUCTION}

Warthin's tumor was first described in the American literature, by Aldred Warthin, in 1929. It is also known as papillary cystadenoma lymphomatosum, or adenolymphoma ${ }^{1}$. It comprises upto $14 \%$ to $30 \%$ of parotid tumors ${ }^{2}$.

\section{CASE REPORT}

A 35-year-old male presented with a swelling in the left parotid region, which was painless and gradually progressing in size. Patient is a smoker since last 6yrs .Swelling measures $5.5 \mathrm{x} 3.5 \mathrm{~cm}$ and was firm in consistency. FNAC was performed under aseptic precautions. Smears were wet fixed immediately in etheralcohol fixative and stained by Papanicolaou and hematoxylin and eosin stains. Air dried smears were stained by Giemsa. Microscopic examination revealed epithelial cells arranged in flat, monolayered sheets (Fig.1), occasionally forming papillary fronds. The epithelial cells were oncocytic in appearance with abundant, densely eosinophilic, granular cytoplasm and round uniform bland nuclei; background showed mixed population of reactive lymphocytes (Fig.2), with abundant cellular debris ${ }^{3}$ along with single, discohesive clusters of degenerating metaplastic squamous cells (Fig.3). Cytological diagnosis of Warthin's tumor was rendered and excision of lump was advised.

Patient underwent complete surgical excision of left parotid gland. The mass was received as multiple cystic to firm fragments, largest measuring $6 \times 4 \times 3 \mathrm{cms}$ and smallest $1.1 \times 1.0 \times 0.7 \mathrm{cms}$. The cystic fragments contained brown colored fluid. Inner surface showed multiple papillary excrescences. Histopathological examination confirmed our cytologic diagnosis of Warthin's tumor with squamous metaplasia. Histomorphology revealed sharply demarcated tumor comprising of oncocytic epithelium arranged in papillary fronds (Fig.4). The stroma was densely infiltrated by lymphoid tissue (Fig .4) forming lymphoid follicles ${ }^{3,4}$.The papillae were lined by double epithelium, inner tall columnar and outer cuboidal cell layer. Squamous metaplasia (Fig. 5) with apocrine differentiation was also noted focally (Fig.6).

\section{DISCUSSION}

Warthin's tumor is most commonly found in parotid gland, but cases have also been reported in sub maxillary gland ${ }^{4}$. In a previous study of 278 cases, all tumors were located in parotid gland ${ }^{5}$. It affects mainly men in the $6^{\text {th }}$ or $7^{\text {th }}$ decade of life ${ }^{3}$. In our case the patient was a young adult but most studies have found an average age at diagnosis in the early sixties ${ }^{6}$. Smokers have 8 times the risk of developing Warthin's tumor. In a study of 533 cases, it was suggested that it is strongly associated with cigarette smoking and that the incidence rate is increasing ${ }^{7}$. It is bilateral and multifocal in $10 \%$ of cases $^{3}$.

The Value of FNAC in diagnosing salivary gland lesions has been widely debated amongst clinicians and cytopathologists ${ }^{8}$. Pre-operative diagnosis of Warthin's tumor poses diagnostic dilemma, since cytologically it simulates many other lesions of salivary glands like low-grade mucoepidermoid, acinic cell carcinoma, squamous cell carcinoma, oncocytic carcinoma, oncocytoma, lymphoepithelial cyst ${ }^{9}$ e.t.c. The most common misinterpretation is squamous metaplasia in association with inflammation or degenerated squamous metaplasia which may be misinterpreted as squamous cell carcinoma ${ }^{10}$. One study examined 9 patients with Warthin tumor 
Fine Needle Aspiration Cytology of Warthin's Tumor: A case report.

who had squamous metaplasia arising in parotid gland ${ }^{11}$.It is rare for a malignant lesion to be misdiagnosed as Warthin tumor but in studies as many as $26 \%$ of Warthin tumors were misdiagnosed as malignant on FNAC $^{10}$.Malignant transformation is very rare ${ }^{4,6} \&$ constitutes $0.3 \%$ of all Warthin tumors ${ }^{6}$.

FNAC has a good diagnostic accuracy in diagnosing salivary gland lesions. Sunil Kumar Y. et al in his study of 343 cases of salivary gland swellings showed that the overall sensitivity, specificity and the diagnostic accuracy were $97 \%, 80 \%$ and $92 \%$ respectively ${ }^{12}$.

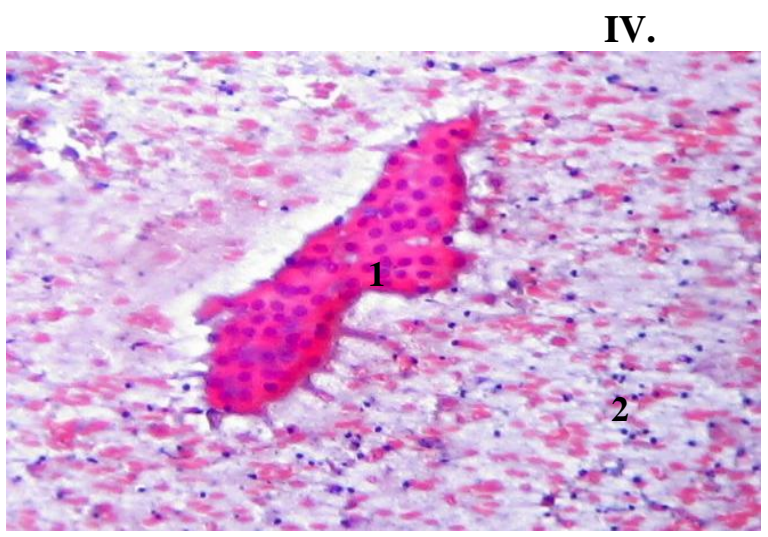

FIGURES

Figure 1 Monolayered sheet of oncocytic cells (Papx4)
Figure 1
1. Oncocytic cells
2. Lymphocytes

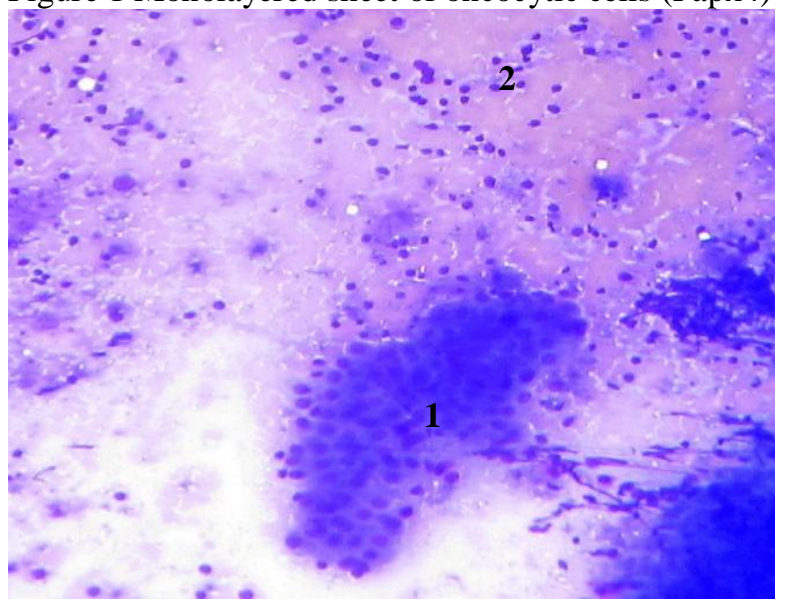

Figure 2

1. Oncocytic cells

2. Lymphocytes

Figure 2 Oncocytic cells in monolayered sheets; background lymphocytes. (MGGx4)

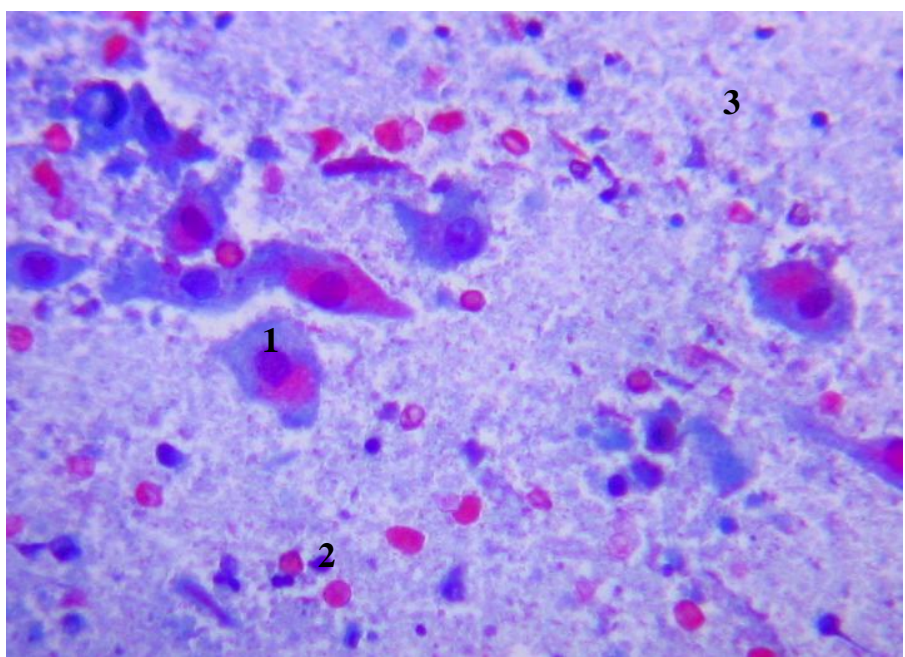

Figure 3

1. Degenerating metaplastic squamous epithelial cells

2. Lymphocytes

3. Cellular debris

Figure 3 Degenerating metaplastic squamous epithelial cells; background lymphocytes and cellular debris (Papx40) 


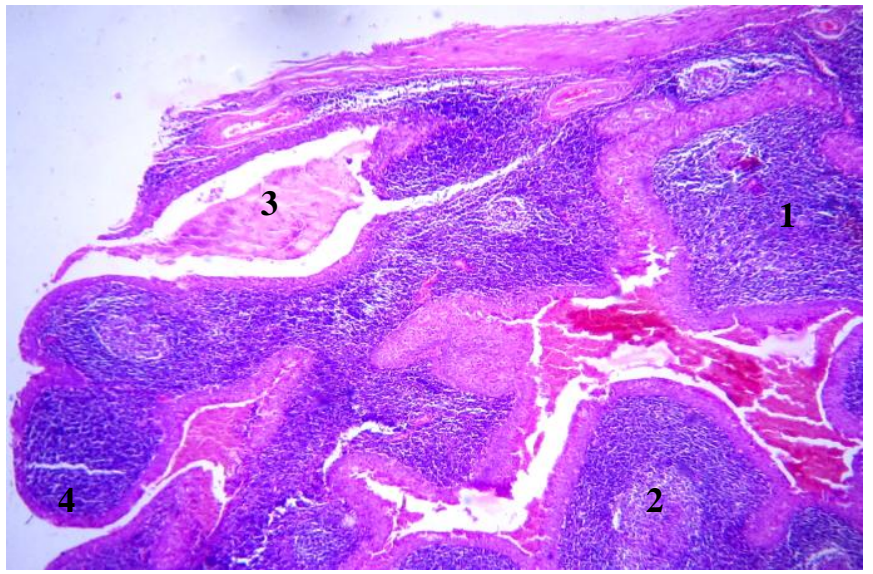

Figure 4

1. Lymphoid stroma

2. Germinal centers

3. Cystic change

4. Papillary fronds

Figure 4 Lymphoid stroma with germinal centres, cystic change and intraluminal papillary fronds (H\&Ex10)

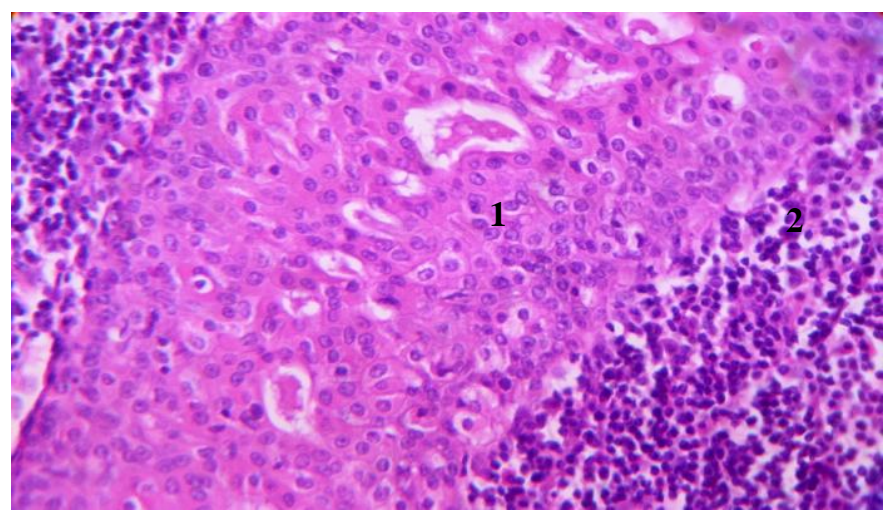

Figure 5

1. Squamous metaplasia

2. Lymphoid stroma

Figure 5 Squamous Metaplasia with underlying lymphoid stroma (H\&Ex40)

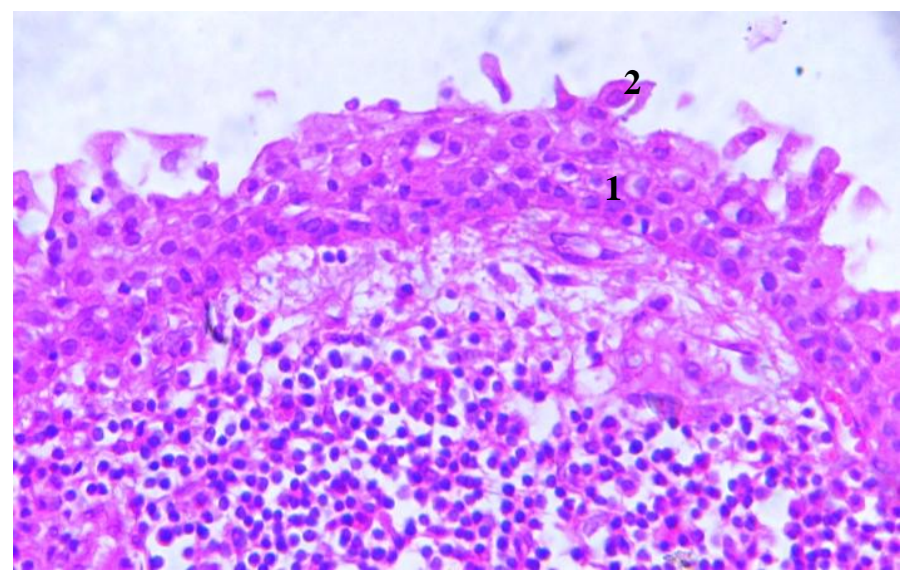
Figure 6
1. Oncocytic cells
2. Apocrine blebs

Figure 6 Luminal layer of palisaded oncocytic cells with apocrine blebs (H\&Ex40)

\section{CONCLUSION}

FNAC of a Parotid swelling is very useful in distinguishing neoplastic from inflammatory lesions, thus helping further surgical management of the patient. However, extreme care \& recognition of limitations of cytology are needed in diagnosing Warthin's tumor.

\section{References}

[1] Warthin AS. Papillary cystadenoma lymphomatosum. A rare teratoid of the parotid region. J Cancer Res 1929; 13:116-25.

[2] Kuladeepa Ananda Vaidya, Doddikoppad. Cytological diagnosis of warthin's tumor: a case report. Asian j Med Res. 2012; 1(2): 2223.

[3] Leopord G. Koss, Koss' Diagnostic Cytology \& its Histopathologic Bases, $5^{\text {th }}$ Ed,Ch-32 "Salivary glands", Vol II ( Philadelphia: Lippincott Williams \& Wilkins, 2006) 1229-1261.

[4] Juan Rosai, Michael Houstan. Rosai \& Ackerman's surgical pathology, $10^{\text {th }}$ Ed, Ch-12 "Major and Minor Salivary Glands", Vol 1 (Mosby, Missouri; Elsevier, 2011) 826-828. 
[5] Eveson J, cawson R. Warthin's tumor (cystadenolymphoma) of salivary glands. A clinicopathological investigations of 278 cases. Oral Surg Med Oral pathol 1986; 61: 256-2.

[6] Robert L.Hatch,MD and Sejal Shah, BS. Warthin Tumor: A Common, Benign Tumor Presenting as a Highly Suspicious Mass. J Am Board Fam Med July -August, 2005 Vol. 18 no. 4: 320-322.

[7] John A. Pinkston1 and Philip Cole. Cigarette Smoking and Warthin's Tumor. Am J Epidemiol Vol. 144, No. 2 , 1996.

[8] Kotwal M, Gaikwad S, Patil R, Munshi M, Bobhate S. FNAC of salivary gland - a useful tool in preoperative diagnosis or a cytopathogist's riddle?. J Cytol 2007; 24:85-8.

[9] Perkins, Mukunyadzi,MD. Review of fine-needle Aspiration of Salivary Gland Neoplasms, With Emphasis on Differential Diagnosis. Am J Clin Pathol 2002; 118(Suppl 1): S100-S115.

[10] Parwani AV, Ali SZ. Diagnostic accuracy and pitfalls in the fine needle aspiration interpretation of Warthin's tumor. Cancer Cytopathology 2003; 99: 166-71.

[11] Di Palma S, Simpson R H Skalova A,Michal M. Metaplastic (infarcted) Warthin's tumor of the parotid gland: a possible consequences of fine needle aspiration biopsy. Histopathology. 1999 Nov; 35(5):432-8.

[12] Sunil kumar Y. et al. Role of Fine Needle Aspiration of Salivary Gland Tumors in Correlation with Their Histopathology: A Two Year Prospective Study. Journal of Clinical and Diagnostic Research. 2011 November (Suppl-2), Vol-5(7): 1375-1380. 